\title{
Research and Analysis on the Development of Express Industry and Living Conditions of Couriers in SC City*
}

\author{
Shijun Yuan \\ Hunan Modern Logistics College \\ Changsha, China
}

\begin{abstract}
At present, China's express industry is developing at a high speed, but couriers generally have low life quality and a heavy work intensity and pressure, and their social support and self-identity need to be further improved. This paper analyzes the development of express industry and problems existing in the working environment and development of couriers, and makes some countermeasure to effectively improve couriers' living conditions.
\end{abstract}

\section{Keywords—express industry; courier; survey analysis}

\section{INTRODUCTION}

In 2018, China's express service companies handled 50.71 billion parcels in total, up $26.6 \%$ year on year, and business revenue reached 603.84 billion yuan, up $21.8 \%$ year on year. A total of 11.41 billion intra-city parcels were handled, with a year-on-year growth of $23.1 \%$. The rapid development of express industry is inseparable from couriers' hard work.

\section{ANALYSIS OF THE SURVIVAL AND SOCIAL IDENTITY STATUS OF COURIERS}

The first-line couriers from 11 express companies, such as SF express, YTO express, ZTO express, STO express, BEST express, Yunda express, etc, in SC city were interviewed by means of questionnaire and interview. A total of 150 questionnaires were sent out and 124 valid questionnaires were recovered. Among the 124 couriers randomly surveyed, 110 of them (accounting for 89\%) are male and 14 of them (accounting for $11 \%$ ) are female. 94 of them $(76 \%)$ are under 30 years old and 94 of them $(76 \%)$ have high school and technical secondary school degree or below.

\section{A. Low Life Quality}

Now, couriers' life quality is generally low, which can be mainly reflected in diet, living and income, and rest and vacation:

1) Irregular life and diet: $55 \%$ of couriers say that their

*Fund: The 2018 Hunan Provincial Philosophy and Social Science Foundation Base Project "Research on the Construction of Hunan Rural Logistics System Based on Rural Revitalization Strategy" (18JD43); Hunan Provincial Social Science Achievement Evaluation Committee's project "Research on Rural Logistics Development Countermeasures System Based on Rural Revitalization Strategy” (XSP19YBC277). meal time is irregular. $31 \%$ of couriers reflect that they can eat on time in the off-season, but have no time to eat during the e-commerce promotion season. $14 \%$ of them hold the opinion that the body is the capital of revolution, and they take a meal on time even no matter how busy or tired they are.

2) No stable place to live: According to the survey, couriers complain about poor dormitory conditions, and only $10 \%$ of them are willing to live in the company's dormitories, and most of them rent a house outside the company. Worse still, due to Changsha's high housing prices and strict purchase restrictions, many couriers deem that they can not afford a house at all in Changsha.

3) Economic income slightly higher than migrant workers' wages: The survey finds that most couriers have a monthly income of 3000-5000 yuan. The distribution proportion of the number of people in different monthly income ranges is shown in the figure below:

The survey on 11 express companies finds that couriers of SF express company make more money than those of other express companies every month.

The reason for the rumor that couriers earn over 10,000 yuan a month is that observer neither have a deep understanding of the operation of express industry, nor make an in-depth investigation on couriers' wage payment mechanism. In the opinion of many couriers, it is possible to have a monthly wage of more than 10,000 yuan in a certain month, but this is only limited to special festivals such as "Double Eleven". However, the company usually does not allow couriers to earn more than 10,000 yuan for two consecutive months, because "if you do two people's work, you will pay a lot, and there will be a lot of troubles for you". In addition, according to the data from National Bureau of Statistics of the People's Republic of China, the monthly income of migrant workers was 3,485 yuan in 2013 (2017 National Migrant Workers Inspection Survey Report by National Bureau of Statistics). The data of this survey shows that the minimum wage for couriers is less than 3,000 yuan, and most couriers earn between 3,000 and 5,000 yuan a month. On the whole, the monthly wage of couriers is not too low compared with the overall average wage of migrant workers. 
colleagues. When faced with problems at work, $71 \%$ of couriers seek help from colleagues and their superior.

4) Helpers for emotional problems: Emotional problems involve personal privacy, so the majority of couriers say that they will not talk about them with colleagues. $63 \%$ of couriers confide in their friends and $34 \%$ of them ask their family members for help.

5) Social satisfaction: Of the 124 couriers surveyed, only 2 of them demonstrate they are dissatisfied with their social status, and $62 \%$ of them are satisfied.

In the survey of occupation identity, $98 \%$ of them believe that couriers exert an important role in social development, and $100 \%$ of them consider that couriers are of great significance to the convenience of people's lives.

However, only $50 \%$ of them deem that they can realize their life value by working as a courier, and $53 \%$ of them are proud of being a courier. $82 \%$ of them feel insulted when someone censures couriers and brings shame on them for no reason.

$15 \%$ of them reflect that there exists theft in the express industry, and $37 \%$ of them say they do not know it clearly.

Of the 124 couriers surveyed, only 34 of them intend to continue working as couriers, accounting for $27 \%$ of the total. 56 of them are not sure about this question, accounting for $45 \%$ of the total.

\section{PRoblems IN THE DEVELOPMENT OF EXPRESS SERVICE INDUSTRY IN SC CITY}

\section{A. Small Company Scale}

There are 188 express service companies in SC city, with an annual sales revenue of 2949.51 million yuan and a net profit of 30.86 million yuan. Main problems in the development process are as follows:

a) Small in number: At present, there are 188 express companies in SC City, only accounting for $0.83 \%$ of the national total, with a small proportion.

b) Small annual income scale: The annual income scale of express service companies in SC city is generally small. Companies with an annual income of less than 20 million yuan account for $94.15 \%$, and only one company has an annual income of exceeding 1 billion yuan.

c) Small asset scale: The assets scale of express service companies in SC city is generally small. 185 companies have assets of less than 50 million yuan, accounting for $98.4 \%$.

d) Short operating period: Express service companies in SC city generally have a short operating period. 127 companies are operating for less than 5 years, accounting for $67.55 \%$. Only 2 companies have more than 15 years of operation, accounting for $1.06 \%$.

e) Small scale of employees in a single company: In SC city, 145 express service companies have less than 20 employees, accounting for $77.13 \%$. Only 16 express service participate in the survey have a good relationship with their 
greater work pressure, and their delivery volume will also be increased.

3) It is hard for couriers to identify their industrial injury. Most express companies pay salaries according to couriers' delivery volume. Many couriers are eager to delivery parcels, and $t \mathrm{t}$ is very easy to for them have accidents when the traffic conditions are complex. In addition, it is easy for them to get tired after repeated work for a long time. There are some health and safety risks in their work. However, due to the lack of labor contract and work-related injury insurance, it is difficult to identify the work-related injury and protect their legitimate rights and interests after the accident.

\section{B. Couriers' Difficulties in Judicial Proceedings}

Couriers will face such problems as lack of professional knowledge of law, high lawyer fees, difficulty in evidence collection, high time cost, and risk of losing the lawsuit when filing a labor lawsuit. In case of the situation that express companies do not conclude labor contracts or pay social insurance, couriers often cannot protect their legitimate rights and interests through litigation. Therefore, it is urgent to establish a litigation mechanism and legal aid system for the protection of the rights and interests of couriers.

\section{CONCLUSION}

In order to effectively improve the quality of survival and life of couriers, it can adopt some measures from the following aspects:

First, it is necessary to clearly define the supervision authority of the express industry supervision department, regularly organize joint inspection team to carry out joint inspections, adopt measures including fines, forfeitures and bans to punish illegal express companies, so as to ensure that the supervision activities are practical and effective.

Second, the relevant departments should give full play to the role of industry associations and regulate market competition. They should also strictly formulate, implement some standards, such as price openness and fairness, advocate signing a self-discipline convention of market competition to regulate the express market, and are committed to standardizing the express delivery market, so as to avoid cutthroat competition in the industry and promote the healthy and sustainable development of the express industry.

Third, the relevant departments should establish "credit archives" for express companies and couriers as soon as possible, and increase the force of supervision on key matters. Based on some factors, such as the service attitude, delivery speed, miss rate of goods, and consumer complaint rate of the express companies, the postal department shall establish "credit archives" for express companies as soon as possible, and classify the express companies into "integrity, lack of integrity and serious dishonesty" and implement the credit classification supervisory system. 


\section{REFERENCES}

[1] Bian Zhiyun. Investigation on the Labor Conditions of Couriers in Beijing [J]. Journal of Beijing Vocational College of Labour and Social Security. 2016 (04) (in Chinese)

[2] Shan Chunlei. Analysis and Protection of Rights and Interests of Couriers [J]. Journal of Sichuan College of Education. 2014(08). (in Chinese)

[3] Chen Juanjuan, You Liyang, Shi Yi, Wang Zhu, Fan Kewei. Research and Analysis of Happiness Status of Suzhou Couriers based on Questionnaire Survey [J]. Science \& Technology Vision. 2018 (04). (in Chinese) 